\title{
Melt-based compression-molded scaffolds from chitosan-polyester blends and composites: Morphology and mechanical properties
}

\author{
V. M. Correlo, ${ }^{1,2}$ L. F. Boesel, ${ }^{1,2}$ E. Pinho, ${ }^{1,2}$ A. R. Costa-Pinto, ${ }^{1,2}$ M. L. Alves da Silva, ${ }^{1,2}$ \\ M. Bhattacharya, ${ }^{3}$ J. F. Mano, ${ }^{1,2}$ N. M. Neves, ${ }^{1,2}$ R. L. Reis ${ }^{1,2}$ \\ ${ }^{1}$ Department of Polymer Engineering, 3B's Research Group-Biomaterials, Biodegradables and Biomimetics, \\ University of Minho, Campus de Gualtar, 4710-057 Braga, Portugal \\ ${ }^{2}$ IBB-Institute for Biotechnology and Bioengineering, PT Government Associated Laboratory, Braga, Portugal \\ ${ }^{3}$ Bioproducts and Biosystems Engineering, University of Minnesota, Minnesota
}

Received 4 December 2007; revised 9 April 2008; accepted 7 July 2008

Published online 4 November 2008 in Wiley InterScience (www.interscience.wiley.com). DOI: 10.1002/jbm.a.32221

\begin{abstract}
Blends of chitosan and synthetic aliphatic polyesters (polybutylene succinate, polybutylene succinate adipate, polycaprolactone, and polybutylene terepthalate adipate) were compounded with and without hydroxyapatite, a bioactive mineral filler known to enhance osteoconduction. The blends and composites were compression molded with two different granulometric salt sizes $(63-125 \mu \mathrm{m}$ and $250-500 \mu \mathrm{m})$ having different levels of salt content $(60,70$, and $80 \%$ ) by weight. By leaching the salt particles, it was possible to produce porous scaffolds with distinct morphologies. The relationship between scaffold morphology and mechanical properties was evaluated using scanning electron microscopy, microcomputed tomography, compression testing, differential scanning calorimetry, small-angle X-ray scattering (SAXS), and wide-angle X-ray scattering. The produced scaffolds are characterized by having different morphologies depending on the average particle size and the amount of $\mathrm{NaCl}$ used. Specimens with higher porosity level have a less organized pore structure but increased intercon-
\end{abstract}

nectivity of the pores. The stress-strain curve under compression displayed a linear elasticity followed by a plateau whose characteristics depend on the scaffold polymer composition. A decrease in the salt particle size used to create the porosity caused in general a decrease in the mechanical properties of the foams. Composites with hydroxyapatite had a sharp reduction in yield stress, modulus, and strain at break. The melting temperature decreased with increased chitosan content. SAXS results indicate no preferential crystalline orientation in the scaffolds. Cytotoxicity evaluation were carried out using standard tests (accordingly to ISO/ EN 10993 part 5 guidelines), namely MTS test with a 24-h extraction period, revealing that L929 cells had comparable metabolic activities to that obtained for the negative control. (C) 2008 Wiley Periodicals, Inc. J Biomed Mater Res 91A: 489-504, 2009

Key words: scaffolds; chitosan; biodegradable blends; polyesters; tissue engineering

\section{INTRODUCTION}

Tissue engineering has recently boosted the interest in producing porous structures for scaffolding in tissue regeneration. The underlying principle in tissue engineering is that cells isolated from a patient are cultured, expanded, and even induced to differentiate in vitro in a cell culture. Still in vitro, the cells

Correspondence to: V. M. Correlo; e-mail: vitorcorrelo@ dep.uminho.pt

Contract grant sponsor: Portuguese Foundation for Science and Technology (FCT); contract grant number: SFRH/BD/22455/2005

Contract grant sponsor: Fundação Luso-Americana para o Desenvolvimento (FLAD)

(C) 2008 Wiley Periodicals, Inc. are seeded onto a scaffold being further matured in vitro, eventually in dynamic culture conditions, after which is implanted back into the patient defect to act as an inductor for regeneration of the tissue. ${ }^{1}$ The porous scaffold provides surface area for further cell expansion and colonization of the whole volume, favoring diffusion of nutrients and metabolites and providing temporary support for the cells.

Ideal scaffolding materials for use in hard tissue engineering must satisfy certain requirements. The materials (and their degradation products) must be noncytotoxic and allow production of biocompatible structures adapted to the tissue to be regenerated. The materials should be biodegradable with an adjustable degradation rate that should match closely the rate of tissue regeneration. The scaffold must also possess mechanical properties adequate to sup- 
port morphogenesis of the neotissue and also to allow for manipulation of the device. It should provide appropriate surface chemistry to facilitate cell attachment, proliferation, and differentiation. Moreover, it should possess the appropriate pore size and interconnected pore network to facilitate extracellular matrix production and tissue ingrowth, enable vascularization to develop, improve oxygen and nutrients supply, and metabolite removal. ${ }^{2}$

Materials that have been evaluated for use in tissue engineering constructs include synthetic polymers, natural polymers, ceramics, metals, and many combinations of the aforementioned types. However, it is highly desirable that the constructs biodegrade, enabling designing temporary systems that maintain available space for the regenerated tissue. Biodegradable aliphatic polyesters such as poly(lactic acid), poly (glycolic acid), polycaprolactone (PCL), and their copolymers are the most widely used synthetic polymers in the field of bone and cartilage tissue engineering.

A natural polymer that has received increased attention in the biomedical field is chitosan. Chitosan can be obtained by alkaline deacetylation of chitin, the second most abundant natural polysaccharide being extracted mainly from the exoskeleton of shellfish. ${ }^{3}$ Because of the $N$-acetyl glucosamine repeating units, the chitosan structure is similar to glucosaminoglycans and seems to mimic their functional behavior. The scientific basis for the utility of $\mathrm{N}$-acetylglucosamine in enhancing the promotion of wound healing is well documented., ${ }^{4,5}$

Studies have been devoted to produce blends of synthetic polymers with chitosan to combine the superior mechanical properties of the synthetic polymers with the biocompatibility and biological interactions of the natural polymer., 6 The properties of a scaffold depend not only on the selected material but also on the technology used for its processing. Methods based on the leaching of soluble particulates are widely employed in the fabrication of $3 \mathrm{D}$ porous structures (scaffolds). ${ }^{8-20}$ By these methods, the porosity can be controlled by varying the amount of leachable particles. The pore size and pore morphology can be adjusted, independent of the porosity, by using particles of different sizes and different morphologies. ${ }^{8,9}$ To improve the structure and to increase the pore interconnectivity of the porous scaffold, particulate leaching has been used in combination with other techniques, namely: solvent casting, $^{9,10}$ gas forming ${ }^{11,12}$ freeze-drying, ${ }^{13}$ injection molding, ${ }^{14}$ extrusion, ${ }^{15}$ and compression molding. ${ }^{8,16,17}$ Some of these methods require the use of organic solvents (e.g., solvent casting followed by particulate leaching). Residual traces of organic solvents used in the process may remain entrapped in the scaffold and eventually damage the cells seeded onto the scaffolds or tissues at the transplantation site. ${ }^{18,19}$
Significant efforts have been made to manufacture porous scaffolds without organic solvents for tissue engineering applications. ${ }^{11,12,18-20}$ One such technology involves melt-based compression molding followed by particulate leaching. The process involves physically mixing a polymer (usually in the powder form) with defined amounts of calibrated leachable particles and loading this powder onto a mold. This is followed by the application of heat and pressure (compression) that result in the melting of the polymeric phase. The compression maximizes the packing of the mixture. The heating process causes the fusion of the polymer particles and promotes the formation of a continuous polymeric network that provide mechanical stability to the structure. The last stage consists in immersing the molded polymerporogen composite in a solvent that selectively dissolves the porogen agent. This methodology has been successfully applied in the production of natural origin starch-based scaffolds. ${ }^{21}$

This study reports on the production of novel scaffolds made from blends of chitosan and biodegradable synthetic aliphatic polyesters produced by the melt-based routine involving compression molding and salt leaching. The motivation for this work was to develop and to produce a new range of chitosanbased scaffolds using novel polymeric matrices in an established melt processing technology. Most of the approaches reported in the literature to produce scaffolds from chitosan-based blends or composites involve the use of solvents, this work being the first reporting the use of a melt-based route. Moreover, the methodologies described in this article are very versatile and avoid the drawbacks associated with solvents and allows producing a large variety of scaffolds with a wide range of porosities and pore morphologies using different polymers. The scaffolds were made with different pore sizes and porosity, aiming at applications in bone and cartilage tissue engineering. We report herein the mechanical and thermal properties and morphology of the newly developed 3D constructs.

\section{MATERIALS AND METHODS}

\section{Materials}

The polyesters used in this study include poly-e-caprolactone (PCL), poly(butylene succinate) (PBS), poly(butylene terepthalate adipate) (PBTA), and poly(butylene succinate adipate) (PBSA). The chitosan used had a degree of deacetylation of $\sim 85 \%$. Polycaprolactone resins PCL 787 (MFI $\sim 4)$, commercially available as $\mathrm{TONE}^{\mathrm{TM}}$ polymer, were obtained from Union Carbide Chemicals and Plastics Division, Bound Brook, New Jersey. Eastar Bio Copolyester $14766^{\mathrm{TM}}$, a butanediol, adipate, and terephthalate copoly- 
mer (MFI 20), was obtained from Eastman Chemical Company, Kingsport, Tennessee. Bionolle ${ }^{\mathrm{TM}}$ 1050, a PBS copolymer (MFI 20), was obtained from Showa Highpolymer Co. Ltd., Tokyo, Japan. The melt flow indices were determined using ASTM test method D 1238 at $190^{\circ} \mathrm{C}$ using a $2.16 \mathrm{~kg}$ load. Hydoxyapatite (grade Capital S) was obtained from Plasma Biotal Ltd. (U.K).

\section{Processing of scaffolds}

The chitosan/polyester blends and composites were compounded in a twin-screw extruder. The details of the processing conditions are described elsewhere. ${ }^{22,23}$ Salt was obtained from a local grocery store. The group of the larger range of $\mathrm{NaCl}$ particles $(250-500 \mu \mathrm{m})$ was obtained by sieving the raw material. The second group $(63-125 \mu \mathrm{m})$ was obtained by grinding the raw material that was further sieved. The compounded blends or composites were ground, mixed with salt, loaded into a mold that was further heated, and compression molded into discs. The salt content was 60 and $80 \%$ by weight for blends and 60 and $70 \%$ by weight for composites containing hydroxyapatite (HA).

The aim of using two different salt amounts and two different salt particle size ranges was to produce scaffolds with varying amounts of porosity and pore sizes and analyze the effect of these parameters on the morphology and mechanical of the developed scaffolds. Some scaffolds were selected to analyze the effect of compression-molding processing method on the crystallinity and thermal properties of the polyester part.

The compression-molded discs were further sliced to obtain cubes with nominal dimensions of $5 \mathrm{~mm}$. The cubes were then immersed in distilled water to leach out the porogen. The water was replaced daily. Preliminary studies had shown that immersing for a period of 6 days would enable the entire salt to leach out. The cubes were dried to constant weight and used for further testing. The various scaffolds composition, levels of porosity and pore size are summarized in Table I.

\section{Mechanical properties}

Uniaxial compression tests were performed on the cubic scaffolds using a Universal tensile testing machine (Instron 4505 Universal Machine). Each specimen measured $5 \mathrm{~mm}$ in the direction of testing and was $5 \mathrm{~mm}$ square in crosssection. Samples were conditioned at room temperature for at least $48 \mathrm{~h}$ before testing. A crosshead speed of $2 \mathrm{~mm} / \mathrm{min}$ was used in the compression tests. The values reported are the average of at least five specimens per condition. The compressive modulus was determined in the most linear region of the stress-strain graph and in the cases that the yield stress was not clear it was calculated as the stress at the intersection of a line drawn parallel to the linear region and intercepting the $x$-axis at $1 \%$ strain.

\section{Morphological analysis}

The cross-section of all the developed scaffolds was analyzed using a Leica-Cambridge S-360 scanning electron
TABLE I

Composition, Porosity and Pore Size of the Scaffolds Produced from Chitosan-Polyester Blends and Salt Particle Size Ranging from 63 to $125 \mu \mathrm{m}$ or 250 to $500 \mu \mathrm{m}$

\begin{tabular}{lcccc}
\hline Composition & $\begin{array}{c}\text { Salt } \\
\text { Particle } \\
\text { Size }(\mu \mathrm{m})\end{array}$ & $\begin{array}{c}\text { Salt } \\
\text { Content } \\
(\text { wt } \%)\end{array}$ & $\begin{array}{c}\text { Porosity } \\
(\%)\end{array}$ & $\begin{array}{c}\text { Pore Size } \\
(\mu \mathrm{m})\end{array}$ \\
\hline 25C-75PBS & $63-125$ & 60 & - & - \\
& & 80 & - & - \\
& $250-500$ & 60 & $57.8 \pm 3.0$ & $226.0 \pm 16.9$ \\
50C-50PBS & $63-125$ & 60 & $54.3 \pm 1.4$ & $109.3 \pm 2.6$ \\
& & 80 & $78.6 \pm 2.5$ & $276.8 \pm 52.5$ \\
& $250-500$ & 60 & $57.7 \pm 6.6$ & $199.3 \pm 5.3$ \\
50C-50PBTA & $63-125$ & 60 & $54.6 \pm 1.5$ & $125.4 \pm 1.4$ \\
& & 80 & $75.8 \pm 1.8$ & $258.5 \pm 15.8$ \\
& $250-500$ & 60 & $55.7 \pm 4.6$ & $202.2 \pm 3.7$ \\
50C-50PCL & & 80 & $73.4 \pm 4.7$ & $232.2 \pm 4.9$ \\
& $63-125$ & 60 & $58.1 \pm 3.0$ & $154.2 \pm 13.1$ \\
& & 80 & $80.6 \pm 1.9$ & $336.0 \pm 35.5$ \\
& $250-500$ & 60 & $62.8 \pm 2.1$ & $212.8 \pm 6.8$ \\
70C-30PBS & & 80 & $76.9 \pm 7.4$ & $266.3 \pm 32.7$ \\
& $63-125$ & 60 & $47.9 \pm 0.7$ & $98.6 \pm 2.3$ \\
& & 80 & - & - \\
& $250-500$ & 60 & $51.7 \pm 1.9$ & $221.3 \pm 4.2$ \\
& & 80 & - & - \\
\hline
\end{tabular}

microscope (SEM) for preliminary assessments on the morphology of the scaffolds. All the samples were sputtercoated with gold prior to SEM observations.

Microcomputed tomography $(\mu \mathrm{CT})$ equipment (SkyScan, Belgium) was used as a nondestructive technique for a very detailed analysis of the morphology of the developed scaffolds using only chitosan-based blends. Four scaffolds of each condition were scanned in high-resolution mode of $8.7 \mu \mathrm{m} x / y / z$ and an exposure time of $1792 \mathrm{~ms}$. The energy parameters defined in the scanner were $63 \mathrm{keV}$ with a current of $157 \mu \mathrm{A}$. Isotropic slice data were obtained by the system and reconstructed in 2D images. These slice images were compiled and analyzed to render $3 \mathrm{D}$ images and obtain quantitative architecture parameters. A $\mu \mathrm{CT}$ analyser and a $\mu \mathrm{CT}$ Volume Realistic 3D Visualization, both from SkyScan, were used as image processing tools for both $\mu \mathrm{CT}$ reconstruction and to create/visualize the $3 \mathrm{D}$ representation. Regions of interest (square of $4.5 \times$ $4.5 \mathrm{~mm}^{2}$ ) were selected in each slice image and thresholded to eliminate background noise. This threshold (to distinguish polymer material from pore voids) was chosen and maintained constant for all the scanned specimens and samples. The threshold was also inverted to obtain pore volume and to analyze both the pore morphology and its interconnectivity.

\section{Differential scanning calorimetry}

The differential scanning calorimetry (DSC) experiments were performed in a Perkin-Elmer DSC7 apparatus using a water cooling accessory and nitrogen as a purge gas (flux 
gas of ca. $\left.20 \mathrm{~cm}^{3} / \mathrm{min}\right)$. Both temperature and heat flux were calibrated with indium $(99.99999 \%$ purity) at a scanning rate of $20^{\circ} \mathrm{C} / \mathrm{min}$. The samples were obtained by cutting a small piece of the scaffold, with about $10 \mathrm{mg}$ weight. All the experiments were performed at $20^{\circ} \mathrm{C} / \mathrm{min}$, starting from room temperature. Only the first run samples were analyzed, which reflects both the type of existing materials and the general morphology developed during processing.

\section{Crystallinity}

Wide-angle X-ray scattering (WAXS) and small-angle $X$ ray scattering (SAXS) experiments on some representative scaffolds were performed using X-ray synchrotron radiation at the Soft Condensed Matter A2 beamline of DESYHASYLAB (Hamburg, Germany). The experimental setup includes a MARCCD detector for acquiring two-dimensional SAXS patterns (sample-to-detector distance being $280 \mathrm{~cm}$ ) and a linear detector for 1D WAXS measurements (distance $23 \mathrm{~cm}$ ).

\section{Cell cytotoxicity assays}

A rat lung fibroblast cell line -L929-, acquired from the European Collection of Cell Cultures, was used to perform cytotoxicity tests. Cells were grown as monolayers in Dulbecco's modified eagle's medium (Sigma, St. Louis, MO) supplemented with $10 \%$ fetal bovine serum (Biochrom, Berlin, Germany) and 1\% of antibiotic-antimycotic mixture $(10,000 \mathrm{U} / \mathrm{mL}$ penicillin G sodium; $10,000 \mathrm{U} / \mathrm{mL}$ streptomycin sulphate; $25 \mu \mathrm{g} / \mathrm{mL}$ amphotericin B) (Gibco, Invitrogen, USA). Trypsin/EDTA $(0.25 \% \mathrm{w} / \mathrm{v}$ trypsin $/ 0.02 \%$ EDTA, Sigma) was used to detach the cells from the culture flasks before the experiments were conducted. Cells were seeded in 96-well plates $(n=6)$ at a density of $1.8 \times$ $10^{4}$ cells/well and incubated for $24 \mathrm{~h}$ at $37^{\circ} \mathrm{C}$, in a humidified atmosphere with $5 \% \mathrm{CO}_{2}$.

The ratio of material weight to extract fluid was constant and equal to $0.25 \mathrm{~g} / \mathrm{mL}$. Latex rubber was used as a positive control of cell death, because it has a strong cytotoxic effect leading to extensive cell death. The ratio of latex material outer surface to extraction fluid was $2.5 \mathrm{~cm}^{2}$ / $\mathrm{mL}$. Culture medium was used as negative control of cytotoxicity, considered to be the ideal situation of cell growth. Test scaffolds $(n=6)$ and positive control were extracted for $24 \mathrm{~h}$ at $37^{\circ} \mathrm{C}$, using complete culture medium as the extraction fluid. Before the tests, culture medium was removed from wells with cells adhered, and an identical volume $(200 \mu \mathrm{L})$ of extraction fluid was added. The cells were left to proliferate in the extract fluid for $72 \mathrm{~h}$. After this period, the extraction fluid was removed, and the serum-free culture medium without phenol red and a substrate-3-(4,5-dimethylthiazol-2-yl)-5(3-carboxymethoxyphenyl)-2(4-sulfofenyl)-2H-tetrazolium (MTS; CellTiter 96 One solution Cell Proliferation Assay kit; Promega, Madison, WI), in a proportion of 5:1, was added to each well. This reaction is based on the reduction of MTS, into a brown formazan product by an enzyme-dehydrogenase-active in all viable cells.
Cells were then incubated for $3 \mathrm{~h}$ at $37^{\circ} \mathrm{C}$ in a humidified atmosphere containing $5 \% \mathrm{CO}_{2}$. After this period, optical density (OD) was measured with a plate reader (Biotek, model Synergy HTi) at $490 \mathrm{~nm}$. The mean OD value obtained was standardized taking into account the values for the negative control.

\section{RESULTS AND DISCUSSION}

\section{Morphological characterization}

The cross-sectional pore morphology of scaffolds after salt leaching was analyzed using SEM. No significant morphological differences were observed between the scaffolds of different polymeric materials produced with both the same range of particle size and same amount of salt. This indicates that material composition does not significantly affect the morphology of the developed scaffolds. However, variations in the amount and/or in the range of $\mathrm{NaCl}$ average particle size affected the porosity and pore structure of the scaffolds.

Considering that material composition did not affect porosity and pore morphology, the produced scaffolds were divided into four groups in order to analyze the effect of the other two variables (salt amount and range of salt particle size) into pore morphology and porosity. Representative SEM images of the four different groups are presented in Figure 1. Qualitative analysis of the scaffolds architecture can be made by studying these images. Increasing the amount of salt particles resulted in an increased porosity and interconnectivity in both salt particle size ranges. Using salt particles with different size range also affected the pore morphology. In the case of using larger salt particle size (250$500 \mu \mathrm{m})$, the pores in the scaffolds mimic the cubic salt crystals with a narrow distribution of average pore size that is consistent with the size of the particles used [Fig. 1(b,d)]. Scaffolds obtained using smaller salt particles $(63-125 \mu \mathrm{m})$ do not show a clear relation between the pore structure and the particle shape [Fig. 1(a,c)]. In these cases, a larger pore size distribution is observed. The average pore size is larger than the particle size used, probably because of clustering of the smaller porogen particles in aggregates. Although there are pores with sizes in the range of $63-125 \mu \mathrm{m}$ as the porogen, when $80 \%$ of salt was used, the majority of the pores have a significantly larger size. These larger pore sizes were observed probably due to aggregate formation of the salt particles that were not disrupted during the mixing process. This observation may be connected with a tendency of the smaller $\mathrm{NaCl}$ grains to aggregate in the presence of trace amounts of moisture. To better understand these results, both groups of 

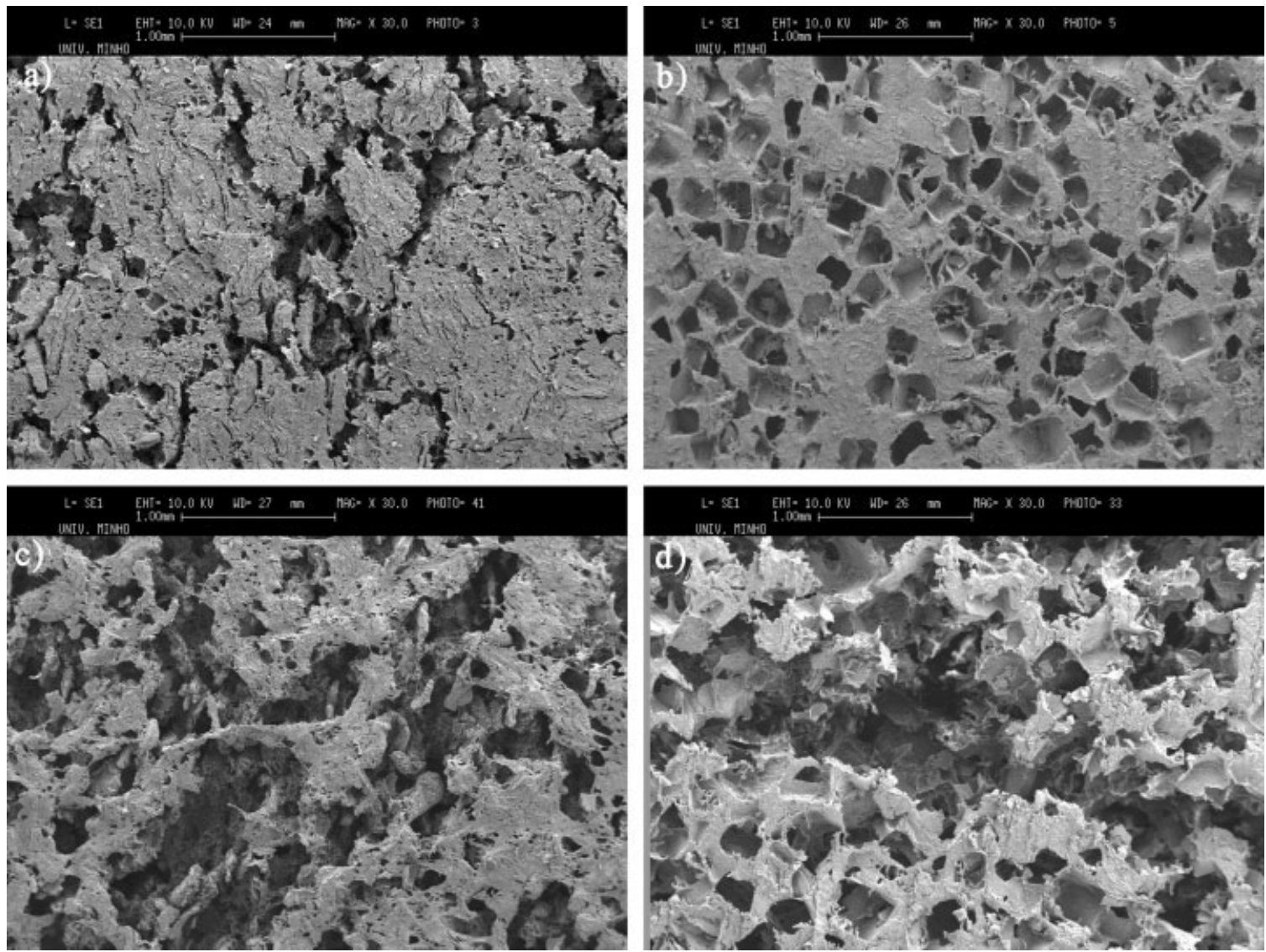

Figure 1. Representative SEM images of the scaffolds obtained with different amounts of salt and different granulometric size particles: (a) $60 \mathrm{wt} \%$ of $\mathrm{NaCl}$ particles with size 63-125 $\mu \mathrm{m}$; (b) 60 wt \% of NaCl particles with size 250-500 $\mu$ m; (c) $80 \mathrm{wt} \%$ of $\mathrm{NaCl}$ particles with size $63-125 \mu \mathrm{m}$; (d) 80 wt \% of NaCl particles with size $250-500 \mu \mathrm{m}$.

particles used in this study were analyzed by optical microscopy using phase contrast mode (Fig. 2), where the tendency to produce aggregates is confirmed.

The grinding procedure also affected the morphology of the salt particles. The morphology of the larger particles (just sieved) presented almost perfect cubic shape [Fig. 2(a)]. Conversely, the smaller particles presented an irregular morphology because of the grinding process that mechanically fragmented the crystals into smaller pieces [Fig. 2(b)]. It was also difficult to observe individual particles when this group was analyzed, as most of them were aggregated in clusters. This indicates that the small particle size had a tendency to aggregate in the presence of humidity, probably because of the larger surface area of the particles. Attempts were made to minimize the agglomeration of smaller particles, such as grinding the polymeric blends to a size similar to the porogen used. This methodology was used for all the scaffolds. This procedure reduced the agglomeration but did not completely eliminate its effects.

Recently, $\mu \mathrm{CT}$ was employed for the observation and analysis of 3D porous scaffolds. ${ }^{24}$ Its advantages include the fact that it is a nondestructive technique that allows analysis the scaffold interior as opposed to SEM that requires sectioning. $\mu \mathrm{CT}$ allows visualizing and measuring the complete three-dimensional volume of the structures without any further sample preparation or chemical fixation.

The 3D scaffolds structure of chitosan-based blends was analyzed using X-ray and $\mu \mathrm{CT}$. For each processing condition, four scaffolds were scanned and analyzed. A representative $2 \mathrm{D} X$-ray image on the region of interest (a square of $4.5 \times 4.5 \mathrm{~mm}$ ) of the four groups of scaffolds is shown in Figure 3. The white regions of these images correspond to material-rich regions, whereas the darker areas correspond to pores. Previous SEM observations were confirmed by analyzing these $2 \mathrm{D} \mu \mathrm{CT}$ images, where a substantial difference exists between porous structures obtained with 60 and $80 \%$ by weight of salt. Pores resulting from the leaching of the larger range of particle size have cubic shape [Fig. 3(b,d)], particularly the pores obtained using $60 \%$ of salt that have a very narrow distribution of pore dimensions. The specimens with larger porosity have less organized pore structure, probably because of contacting adja- 

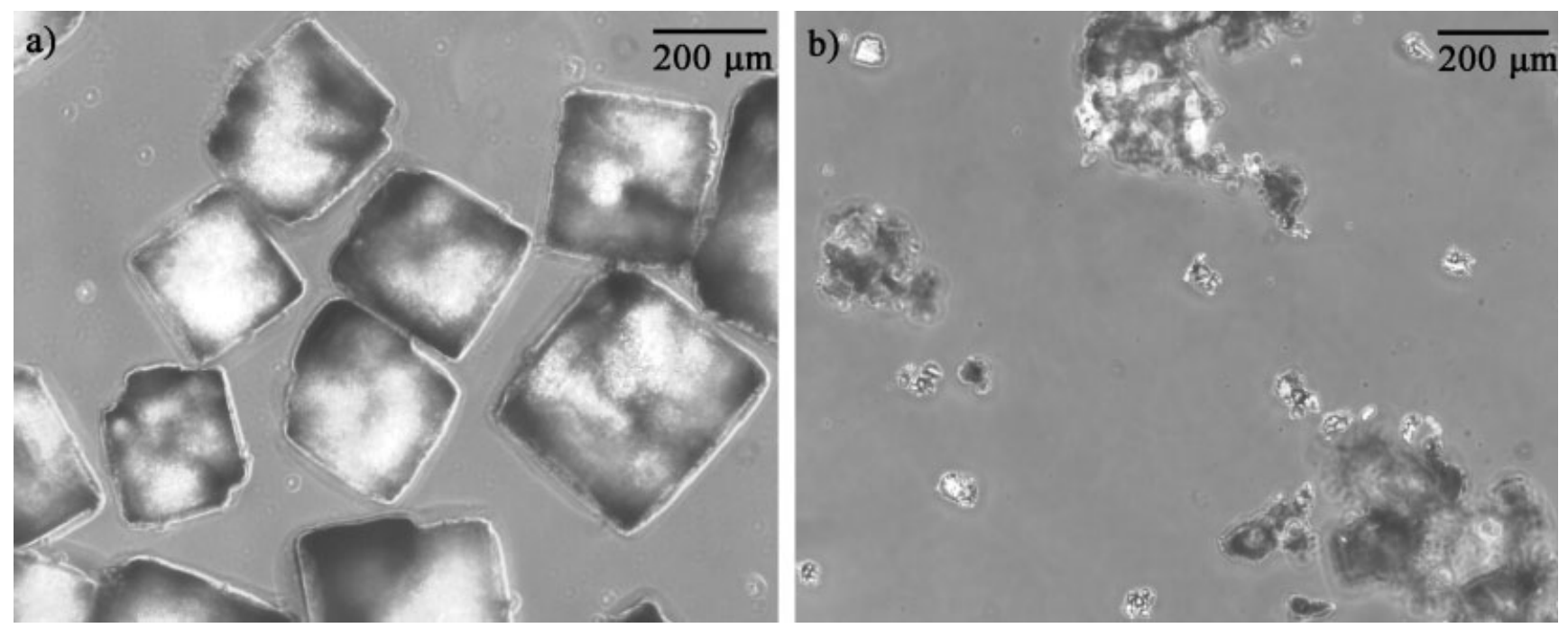

Figure 2. Optical microscopy using phase-contrast mode images of the different salt particles: (a) particle size between 250 and $500 \mu \mathrm{m}$; (b) particle size between 63 and $125 \mu \mathrm{m}$.
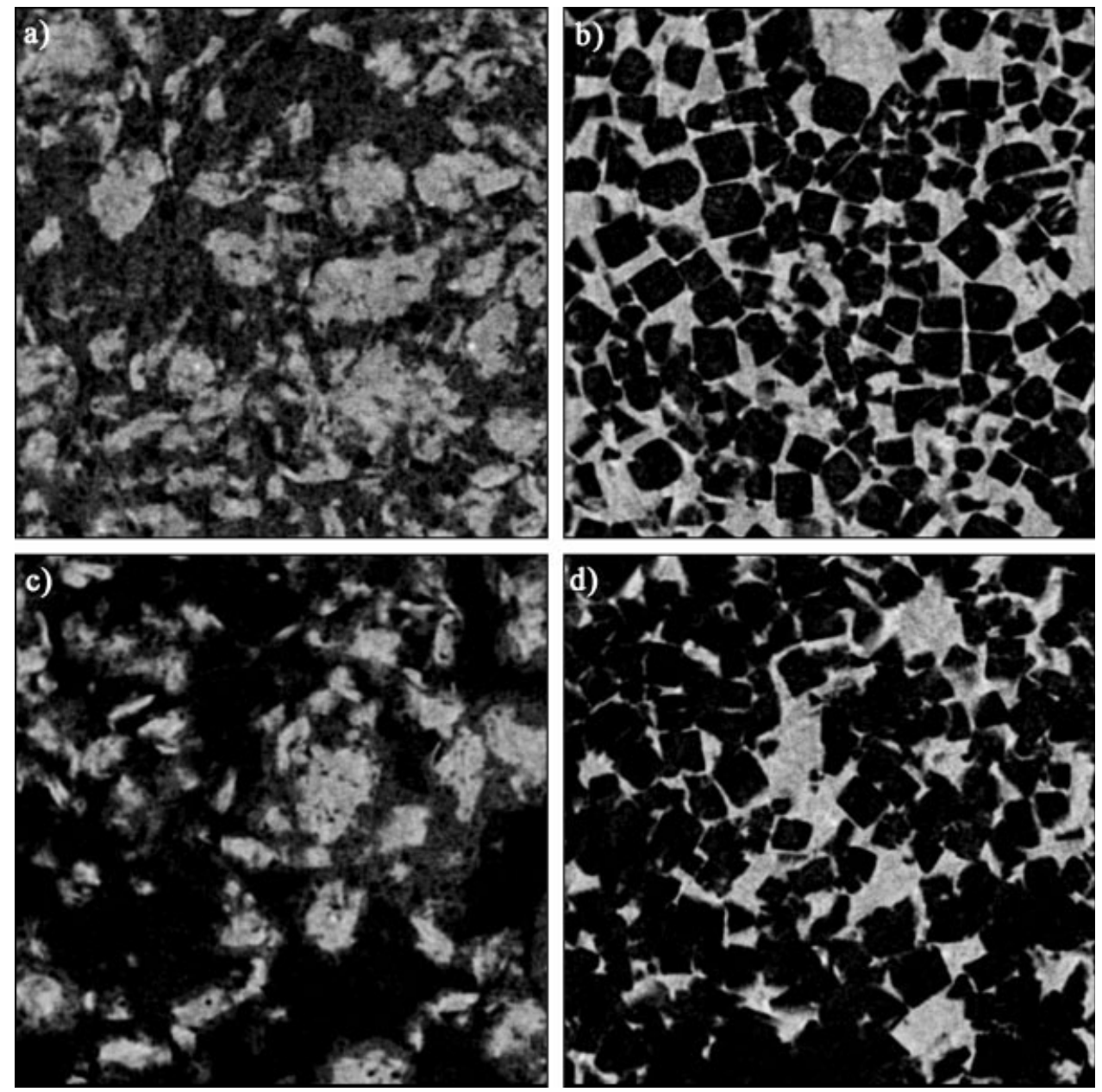

Figure 3. Representative $2 \mathrm{D} \mu \mathrm{CT}$ images (corresponding to the region of interest) of the scaffolds obtained using chitosan-based blends with different amounts of salt and different granulometric size particles: (a) $60 \mathrm{wt} \%$ of $\mathrm{NaCl}$ particles with size 63-125 $\mu \mathrm{m}$; (b) 60 wt \% of $\mathrm{NaCl}$ particles with size 250-500 $\mu \mathrm{m}$; (c) 80 wt \% of $\mathrm{NaCl}$ particles with size 63$125 \mu \mathrm{m}$; (d) $80 \mathrm{wt} \%$ of $\mathrm{NaCl}$ particles with size $250-500 \mu \mathrm{m}$. 

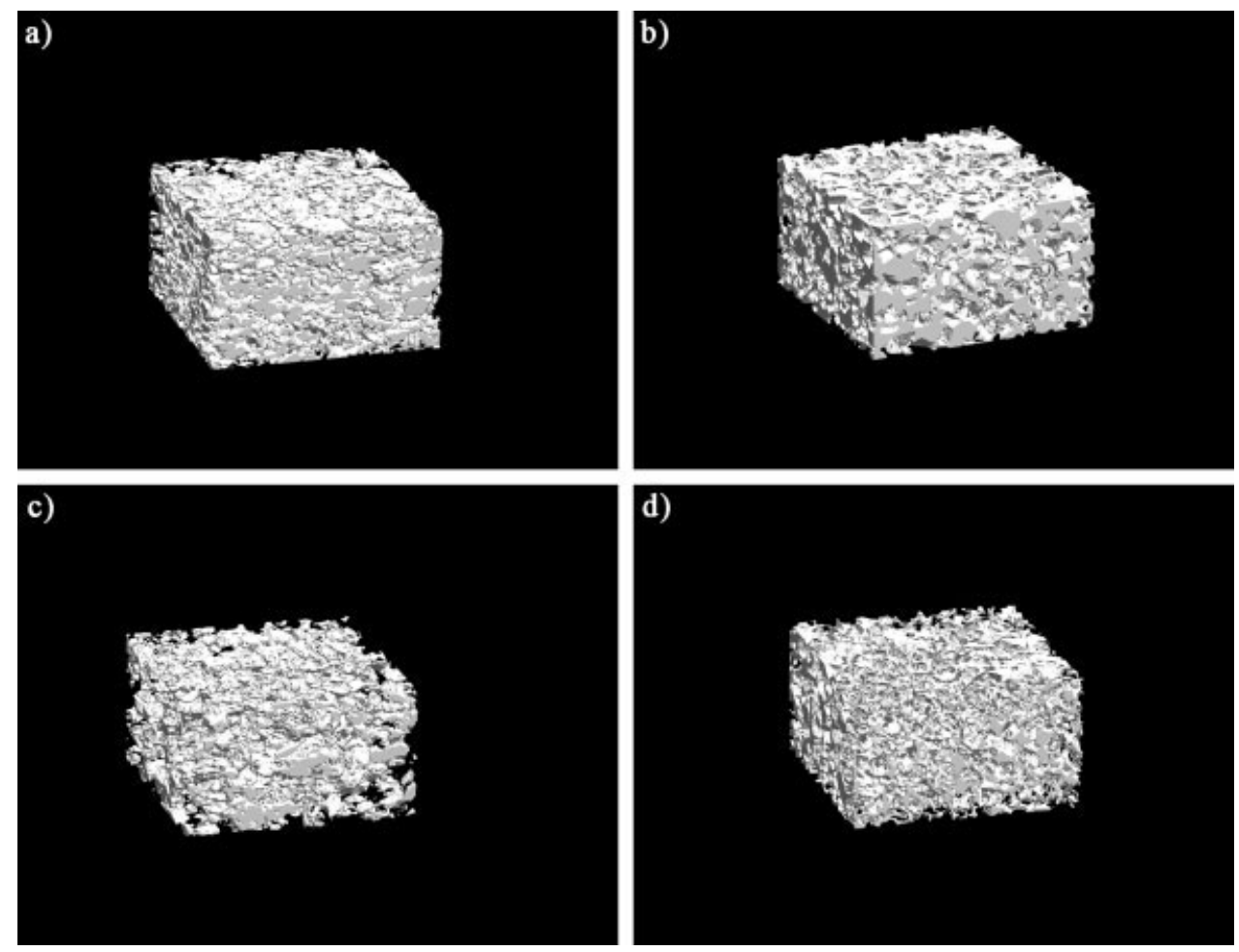

Figure 4. Representative 3D $\mu \mathrm{CT}$ images of the entire scaffolds obtained using chitosan-based blends with different amounts of salt and different granulometric size particles: (a) $60 \mathrm{wt} \%$ of NaCl particles with size 63-125 $\mu \mathrm{m}$; (b) $60 \mathrm{wt} \%$ of $\mathrm{NaCl}$ particles with size $250-500 \mu \mathrm{m}$; (c) 80 wt \% of $\mathrm{NaCl}$ particles with size $63-125 \mu \mathrm{m}$; (d) 80 wt \% of NaCl particles with size $250-500 \mu \mathrm{m}$.

cent particles. As a result, an increased interconnectivity of pores is observed. Samples obtained using the smaller particle sizes have pores with relatively unrelated shape [Fig. $3(\mathrm{a}, \mathrm{c})]$. The pores on those scaffolds indicate the leaching of clusters of particles. The resulting pores resemble small tunnels interconnected across the entire scaffold volume. Because of the probable agglomeration, it appears that the scaffolds obtained with the smaller particle sizes possess higher interconnectivity than the ones obtained using the larger particle size. This is consistently observed for both porosities.

The images of the region of interest were threshold and binary images were obtained (figure not shown). For all the analyzed scaffolds, a dynamic threshold ranging from 255-60 gray scale values was used to distinguish polymer material from pore voids. This setting was used for all the scanned specimens. Individual 2D analysis of the binary images (with a region of interest of $4.5 \times 4.5 \mathrm{~mm}^{2}$ ) obtained along the scaffold cross-section consisting of 300 slices was performed for morphometry calculations. The total porosity and pore size of each scaffold specimen (Table I) was obtained as the average of the individual porosity and pore size of the 300 slices of each scaffold. For each condition, four scaffolds were analyzed. As expected, the volumetric porosity depends on the amount of porogen particles used, and in all the cases was very similar to the amount of salt used, whereas no significant influence of the $\mathrm{NaCl}$ particle size was observed on those results. The average pore size of the scaffolds is strongly affected by both particle size and particle amount. In scaffolds prepared with $60 \mathrm{wt} \%$ of salt with a particle size range of 250-500 $\mu \mathrm{m}$, the observed average pore size is smaller than expected. This result indicates that the sieving process is not sufficiently accurate to allow controlling the pore size in the scaffolds after porogen removal. When the amount of salt was set at $80 \mathrm{wt} \%$, there was a marginal increase on the average pore size. However, this variation was more pronounced when $80 \mathrm{wt} \%$ of salt with particle size of $63-125 \mu \mathrm{m}$ was used, being in most of the cases larger than when the porogen particles with the granulometric size range of $250-500 \mu \mathrm{m}$ was used. This is a clear indication that the smaller particles are more prone to agglomeration probably because of the environmental humidity. This result also confirms previous SEM observations, where smaller porogen particles led to larger average pore size in the scaffolds.

Using a $\mu$ CT-analyser (CTan), 3D models of the different scaffolds were made using a square region of interest $\left(4.5 \times 4.5 \mathrm{~mm}^{2}\right)$ and a length of 300 slices (Fig. 4). To analyze the morphology in the bulk of the scaffold, 3D models were made using only 50 sli- 
ces (figure not shown). In both cases, a dynamic threshold in the range 255-60 gray scale was used. No significant differences were observed between the bulk and the global morphology of the scaffolds. As expected, the architecture of the scaffolds is deeply affected by the amount of salt and by the salt particle size range used.

By inverting the threshold, a negative image of the scaffolds was created (figure not shown). This image corresponds to the volume of the pores and allowed to visualize the pore morphology and also to evaluate pore interconnectivity. As observed previously, the morphology of the pores changed when salt amount and particle size range were varied. The pores obtained using the larger range of particles mimicked the perfect cubic shape of the $\mathrm{NaCl}$ particles used (figure not shown). As the porosity was increased from 60 to $80 \%$, this effect was less visible due to the increased number of contact points between the adjacent particles, causing more difficulties in identifying pores with perfect cubic shape. This effect resulted in the improvement of the interconnectivity. The pores produced with the smaller range of porogen particles resulted mostly from the leaching of clusters of $\mathrm{NaCl}$ particles. These pores have an undefined morphology with a larger distribution of average pore diameter.

The use of smaller range of particles also resulted in scaffolds with a higher degree of interconnectivity of the pore network. This is particularly visible when the higher porosity scaffolds were analyzed.

\section{Mechanical properties}

The nominal stress-nominal strain curve for the various polyesters and their blends for differing porosities and pore sizes are shown in Figures 5-9. Stress is defined as the load per total area of the specimen, while strain is calculated on the entire structure and not on the microscopic strain in the cell walls. The compressive modulus was calculated as the slope of the most linear region of the stressstrain curve prior to the yield point. The compressive stress was calculated as the maximum stress prior to the collapse of the porous construct. All tests were conducted on the specimen with identical dimensions, since the specimen size affects its mechanical properties. ${ }^{25}$

The stress-strain curves of most of the scaffolds exhibit qualitative characteristics similar to that of metallic or polymeric foams. ${ }^{26-28}$ The shape of the curve varies with the amount of porosity, pore size, composition, and the type of polyester. At the initial stage of compression, an elastic region is observed that is followed by a peak stress for scaffolds obtained with all materials. This linear elastic region is related to cell-edge bending in open-cell foams. ${ }^{26}$ The peak stress is typically associated with the beginning of crack initiation where the cell walls start to buckle. A distinct yield point after the elastic region may be observed in some cases. After this initial stage, the curve changes to a regime of very strong plastic flow characterized by a significant change in the slope of the stress versus strain curve. For some compositions (Fig. 5), the curve is horizontal, that is, the stress does not change during large strain levels (blends containing PBTA and PBSA). In other compositions, the plastic regime is not associated with a flat plateau, but the stress continues to monotonically increase with strain (blends containing PCL Fig. 5). In this region, as stress increases, the cells begin to collapse by elastic buckling, yielding, or fracture, depending on the nature of the predominant cell wall material. ${ }^{29}$ This region corresponds to a high-energy absorption, where the space occupied by the hollow pores is filled by materials that are being compressed. Following the extended plateau regime (Fig. 5), the stress-strain curve changes into the regime of densification. In this regime, the cell wall touches each other cell walls, and it is accompanied by a steep increase in stress. At higher strain, the rupture causes the cell walls to break into small pieces, squeezing it and causing the stress to increase.

Pure polyesters display a smooth stress-strain curve (Fig. 6). In these samples, the yield points are less obvious. The plateau stress is not identifiable in these scaffolds as the materials did not fracture; rather, the scaffolds continue to strain harden at all strains. This behavior is also observed for blends containing 25\% chitosan and 75\% PBS (Fig. 7) and

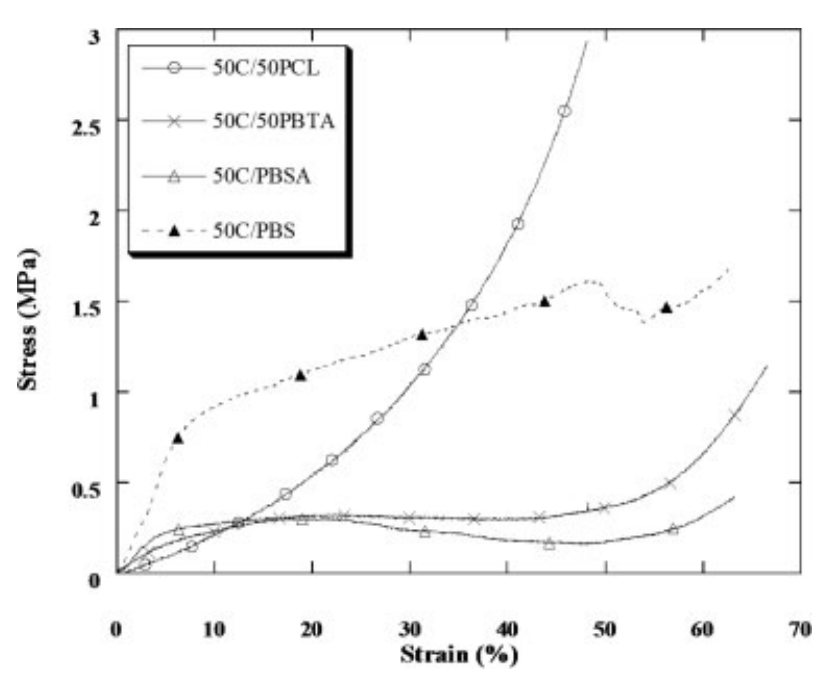

Figure 5. The effect of polyester type on the stress-strain plot of scaffolds having $50 \%$ chitosan and a porosity of $80 \%$ with particle size range between 63 and $125 \mu \mathrm{m}$. 


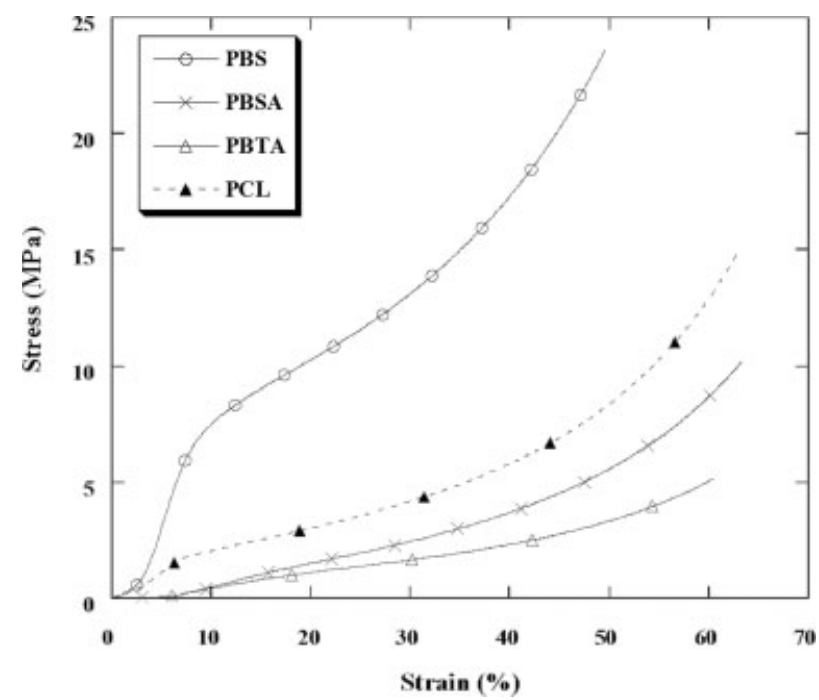

Figure 6. Stress-strain plot of polyester scaffolds with $60 \%$ porosity with particle size range between 250 and $500 \mu \mathrm{m}$.

the low-porosity blends of $50 \%$ chitosan and $50 \%$ PBTA (figure not shown). In these materials, a partial collapse of some parts of the scaffolds was observed while the remaining part still behaved elastically. Alternately, the cell walls could undergo plastic yielding throughout the deformation range. The strain at which densification occurs for pure polyesters is larger than those that occur in the blends.

The stress-strain curves for blends of chitosan and polyester are shown in Figures 5 and 7. The stressstrain behavior is affected by the type of polyester used in the blend. For blends of $50 \%$ chitosan $/ 50 \%$ PCL (at $\sim 60 \%$ and $\sim 80 \%$ porosity), $50 \%$ chitosan/ PBTA ( $60 \%$ porosity), and $25 \%$ chitosan $/ 75 \%$ PBS ( $\sim 60 \%$ and $\sim 80 \%$ porosity), the stress-strain behavior is similar to that of the pure polyester. For the scaffolds produced using larger salt particle size, as the chitosan content increased, the modulus increased. The yield stress reached a maximum with $50 \%$ of chitosan, decreasing for the material with $70 \%$ of chitosan (Fig. 7). For the scaffolds obtained with smaller particles, both the yield stress and modulus decreased with increasing chitosan content. The addition of HA causes a significant reduction in both the strength and the modulus. These are immiscible blends, and earlier studies have already shown ${ }^{23}$ that HA displays poor adhesion to the chitosan/polyester matrix.

The values for the compressive yield stress and modulus for various specimens are listed in Table II. At similar pore size, increasing the porosity decreased the yield stress and the modulus. This was an expected result, since a higher amount of porosity corresponds to a smaller volume of material sustaining the stress. Scaffolds prepared using larger particle size ranges show higher compressive modulus than the ones prepared using particles of lower size (with the exception of PBTA blends). Similar results were reported in the literature by other research groups. ${ }^{30,31}$ This result is in accordance with the previous morphological analyses showing that the scaffolds prepared with larger particle size possess pores with a more organized and defined structure and apparently having lower interconnectivity than do the ones prepared using smaller particle size. Pore interconnectivity makes the structure more brittle, reducing scaffold stiffness. Decreasing the salt particle size also decreased the yield stress of the foams. Gibson and Ashby ${ }^{29}$ analyzed the collapse stress of porous metal and concluded that the collapse stress is unaffected by the pore size. Following the analysis outlined by Landers et al. ${ }^{32}$ it can be shown that for scaffolds having the same porosity the strut diameter is proportional to the pore size. Euler's buckling load is proportional to the fourth power of strut diameter and inversely proportional to the square of strut length (which approximately equals pore size). Hence, scaffolds with smaller pore size have reduced yield strength (Table II). In addition, it has been reported that cell wall curvature reduces the mechanical properties below values that would be expected if the walls were planar. ${ }^{26}$ It is apparent that the shape of larger salt particles is $\mathrm{cu}-$ bical while that of the smaller size salt particle is less defined but without sharp edges (Fig. 2). This results in a scaffold with planar walls for larger salt particle [Fig. 3(b,d)] versus rounder walls for smaller particle size [Fig. 3(a,c)].

The addition of chitosan content into the blends increased the compressive modulus of the scaffolds produced using the PCL and PBTA blends. In the

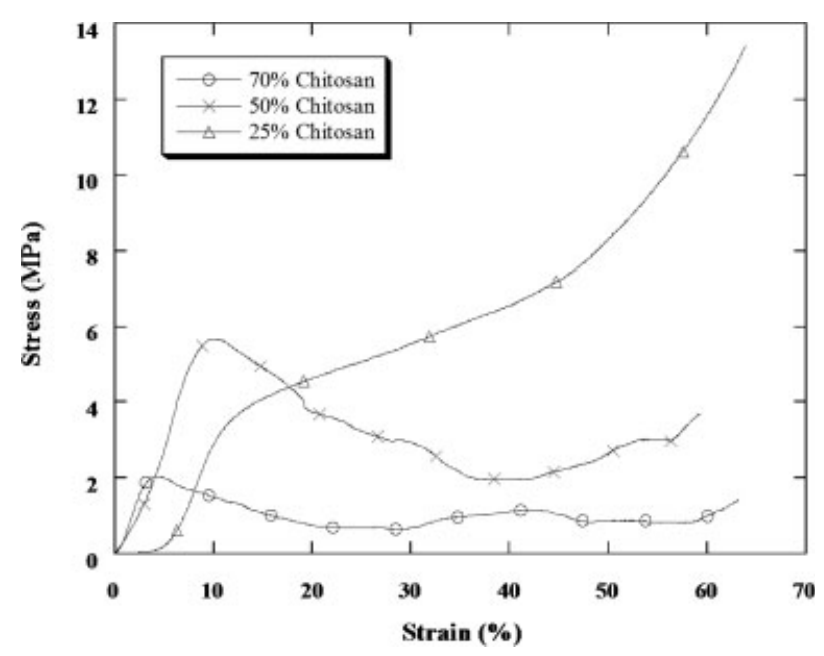

Figure 7. Effect of chitosan content on polybutylene succinate scaffold with a porosity of $60 \%$ with particle size range between 250 and $500 \mu \mathrm{m}$. 
TABLE II

Mechanical Properties of the Scaffolds Produced from Chitosan-Polyester Blends and Salt Particle Size Ranging from 63 to $125 \mu \mathrm{m}$ or 50 to $500 \mu \mathrm{m}$

\begin{tabular}{|c|c|c|c|c|}
\hline Composition & $\begin{array}{l}\text { Salt Particle } \\
\text { Size }(\mu \mathrm{m})\end{array}$ & $\begin{array}{l}\text { Salt Content } \\
\text { (wt \%) }\end{array}$ & $\begin{array}{l}\text { Compressive } \\
\text { Modulus (MPa) }\end{array}$ & $\begin{array}{l}\text { Yield Stress } \\
\quad(\mathrm{MPa})\end{array}$ \\
\hline \multirow{4}{*}{$\overline{\mathrm{PCL}}$} & 63-125 & 60 & $32.4 \pm 19.9$ & $1.5 \pm 0.4$ \\
\hline & & 80 & $2.7 \pm 1.4$ & $0.05 \pm 0.01$ \\
\hline & $250-500$ & 60 & $48.1 \pm 17.7$ & $3.1 \pm 2.9$ \\
\hline & & 80 & $5.3 \pm 1.7$ & $0.5 \pm 0.2$ \\
\hline \multirow[t]{4}{*}{ PBTA } & 63-125 & 60 & - & - \\
\hline & & 80 & - & - \\
\hline & $250-500$ & 60 & $7.0 \pm 2.0$ & $0.5 \pm 0.1$ \\
\hline & & 80 & $4.0 \pm 3.0$ & $0.2 \pm 0.1$ \\
\hline \multirow[t]{4}{*}{ PBSA } & $63-125$ & 60 & - & - \\
\hline & & 80 & - & - \\
\hline & $250-500$ & 60 & $19.0 \pm 11.0$ & $2.4 \pm 0.9$ \\
\hline & & 80 & $7.0 \pm 4.0$ & $0.2 \pm 0.1$ \\
\hline \multirow[t]{4}{*}{ PBS } & 63-125 & 60 & $106.3 \pm 44.6$ & $6.3 \pm 3.5$ \\
\hline & & 80 & $12.7 \pm 4.4$ & $0.3 \pm 0.2$ \\
\hline & $250-500$ & 60 & $212.2 \pm 77.5$ & $14.9 \pm 7.2$ \\
\hline & & 80 & - & - \\
\hline \multirow[t]{4}{*}{ 25C-75PBS } & $63-125$ & 60 & $106 \pm 34$ & $9.9 \pm 3.1$ \\
\hline & & 80 & $9.0 \pm 3.0$ & $0.3 \pm 0.2$ \\
\hline & $250-500$ & 60 & $64.3 \pm 22.9$ & $2.8 \pm 0.5$ \\
\hline & & 80 & $12.4 \pm 3.3$ & $0.4 \pm 0.3$ \\
\hline \multirow[t]{4}{*}{ 50C-50PBS } & $63-125$ & 60 & $39.0 \pm 7.4$ & $1.1 \pm 0.5$ \\
\hline & & 80 & $1.7 \pm 0.4$ & $0.05 \pm 0.01$ \\
\hline & $250-500$ & 60 & $87.4 \pm 21.6$ & $3.8 \pm 1.4$ \\
\hline & & 80 & $12.1 \pm 3.3$ & $0.4 \pm 0.1$ \\
\hline \multirow[t]{4}{*}{ 50C-50PBSA } & 63-125 & 60 & $6.2 \pm 2.8$ & $0.43 \pm 0.2$ \\
\hline & & 80 & $0.5 \pm 0.1$ & $0.02 \pm 0.01$ \\
\hline & $250-500$ & 60 & $14.0 \pm 6.4$ & $0.9 \pm 0.4$ \\
\hline & & 80 & $5.6 \pm 3.3$ & $0.2 \pm 0.1$ \\
\hline \multirow[t]{4}{*}{ 50С-50РВТА } & 63-125 & 60 & $7.9 \pm 02.5$ & $0.1 \pm 0.03$ \\
\hline & & 80 & $1.6 \pm 0.3$ & $0.02 \pm 0.01$ \\
\hline & $250-500$ & 60 & $21.8 \pm 7.8$ & $1.1 \pm 0.8$ \\
\hline & & 80 & $6.3 \pm 1.3$ & $0.3 \pm 0.1$ \\
\hline \multirow[t]{4}{*}{ 50C-50PCL } & $63-125$ & 60 & $42.0 \pm 12.8$ & $1.3 \pm 0.8$ \\
\hline & & 80 & $5.7 \pm 3.1$ & $0.05 \pm 0.02$ \\
\hline & $250-500$ & 60 & $53.1 \pm 23.7$ & $2.2 \pm 1.6$ \\
\hline & & 80 & $5.5 \pm 3.3$ & $0.1 \pm 0.05$ \\
\hline \multirow{4}{*}{ 70C-30PBS } & $63-125$ & 60 & $9.0 \pm 2.3$ & $0.1 \pm 0.05$ \\
\hline & & 80 & $3.0 \pm 1.8$ & $0.08 \pm 0.01$ \\
\hline & $250-500$ & 60 & $47.0 \pm 27.1$ & $1.1 \pm 0.7$ \\
\hline & & 80 & $5.0 \pm 5.0$ & $0.04 \pm 0.02$ \\
\hline
\end{tabular}

case of the scaffolds produced using PBS and PBSA blends, the addition of chitosan resulted in an opposite effect. This behavior was observed independently of the pore size for both cases. The chitosan content caused a small variation in the yield stress but a significant difference in the strain at yield (data not shown). This observation is common for all the samples, independent of composition and porosity, except for samples containing $70 \%$ chitosan. The stress-strain diagrams show no yielding point. The stress decreases sharply after the peak, and at $\sim 20$ $30 \%$ strain, the samples collapsed (stress $\sim 0$ ). The scaffolds produced with other brittle materials $(50 \%$ chitosan $/ 50 \%$ PBS, and 70\% chitosan $/ 30 \%$ PBS) have an oscillating plateau region. This region is marked by progressive collapse occurring as a result of con- tinued deformation of existing cracks as well as by the formation of new ones. As strain progresses, the structure is further compressed, and densification causes the stress to raise again until the next fracture that releases the stress again. This is responsible for the oscillations in stress. The drop in stress is observed for stress levels between 50 and $60 \%$ of the peak stress. Reproducibility, particularly for the high porosity samples of the aforementioned blends, is poor. This is probably because of difficulties in cutting the specimens as well as by any unintended anisotropy of the pore structure. During the early stages of compression, at the initiation of crack, the brittle nature of the scaffolds leads to the formation of powder material and some mass loss due to fragments detaching from the scaffolds. 


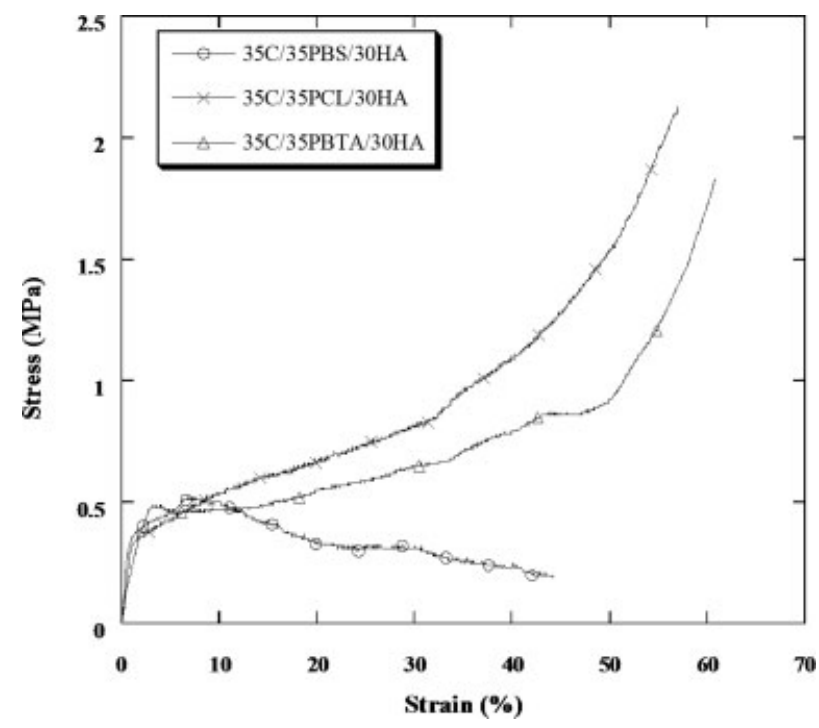

Figure 8. Effect of polyester type on the stress-strain behavior of $70 \%$ porosity scaffolds.

The stress-strain curves of scaffolds obtained using composites containing chitosan/polyester and HA are shown in Figures 8 and 9. These scaffolds were produced using just the higher salt particle size range. The value for yield strength and compressive modulus is given in Table III. Composites of chitosan and hydoxyapatite with either PCL or PBTA are able to carry loads to strains well beyond their ultimate strains. The exceptions are composites containing 50\% chitosan and PBS with HA (Fig. 8) where a linear increase is observed after which the stress decreases for increasing strains. In these materials, the densification process, apparent in the more ductile material, seems to be absent. The specimens fail

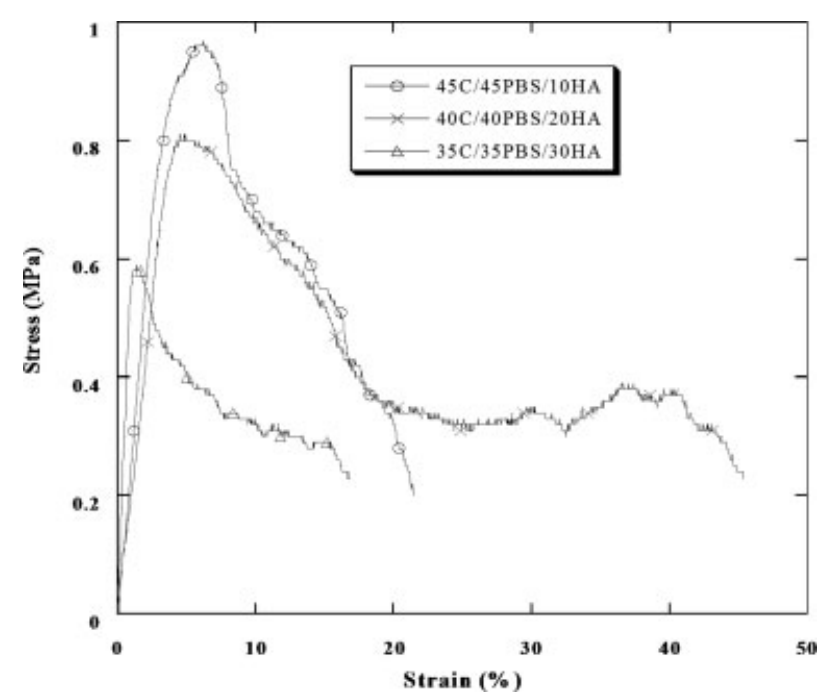

Figure 9. Effect of hydroxyapatite content on the stressstrain behavior of $60 \%$ porosity scaffolds.
TABLE III

Mechanical Properties of Scaffolds Containing Hydroxyapatite Produced Using Salt Particles with Size Ranging from 250 to $500 \mu \mathrm{m}$

\begin{tabular}{lccc}
\hline \multicolumn{1}{c}{ Composition } & $\begin{array}{c}\text { Salt } \\
\text { Content } \\
(\%)\end{array}$ & $\begin{array}{c}\text { Compressive } \\
\text { Modulus } \\
(\mathrm{MPa})\end{array}$ & $\begin{array}{c}\text { Yield } \\
\text { Stress } \\
(\mathrm{MPa})\end{array}$ \\
\hline 70PBS/30HA & 60 & $100 \pm 19$ & $4.6 \pm 1.8$ \\
17.5C/52.5PBS/30HA & 70 & $52 \pm 20$ & $1.3 \pm 1.1$ \\
& 70 & $67 \pm 14$ & $2.7 \pm 0.5$ \\
45C/45PBS/10HA & 60 & $35 \pm 25$ & $0.9 \pm 0.5$ \\
& 70 & $21 \pm 9$ & $0.3 \pm 0.2$ \\
40C/40PBS/20HA & 60 & $85 \pm 9$ & $0.2 \pm 0.1$ \\
& 70 & $25 \pm 11$ & $0.6 \pm 0.4$ \\
35C/35PBS/30HA & 60 & $48 \pm 12$ & $0.6 \pm 0.2$ \\
& 70 & $38 \pm 29$ & $0.5 \pm 0.3$ \\
35C/35PCL/30HA & 60 & $102 \pm 18$ & $2.1 \pm 0.7$ \\
& 70 & $74 \pm 27$ & $0.5 \pm 0.2$ \\
35C/35PBTA/30HA & 60 & $43 \pm 5$ & $0.5 \pm 0.1$ \\
& 70 & $25 \pm 18$ & $0.1 \pm 0.04$ \\
\hline
\end{tabular}

by a brittle process and an abrupt loss of load carrying capacity after attaining peak stress. The failure initiates in the region having the lowest density or clusters of defects or weaker regions. The probability of weak regions is significantly higher in the highporosity samples than in samples with lower porosity. As the HA content in the blend increased (Fig. 9), both yield stress and strain at failure decreased. Addition of HA led to a decrease in the compressive yield stress for all blends. The compressive modulus was also lower for blends containing HA, except for scaffolds containing PCL. Similar results were observed on compact injection-molded tensile testing samples. ${ }^{23}$ Morphological observations using SEM indicate $^{23}$ that HA particles have minimal adhesion to the chitosan/polyester matrix and debond easily during deformation, thus not contributing significantly to the stiffening of the material.

The foams can be construed to be made up of interconnected beams. In open-cell foams, the cell edges initially deform by bending. Cell struts in foams subjected to compressive loading fail either by elastic buckling when the maximum compressive stress exceed the Euler buckling load, or by crushing when the maximum stress exceeds the modulus of rupture, ${ }^{33}$ that is, the strength of foams is dependent on the strength of the struts parallel to the direction of the applied load. Euler buckling load depends on the elastic modulus and slenderness of the individual cell walls. Hence, materials with lower elastic modulus also display lower compressive yield strength. Brittle crushing occurs when the critical skin stress exceeds the cell-wall modulus. The failure stress and cell-wall modulus depend on cell size, relative density, and Weibull modulus, which is related to the properties of cracks and flaw size distribution 


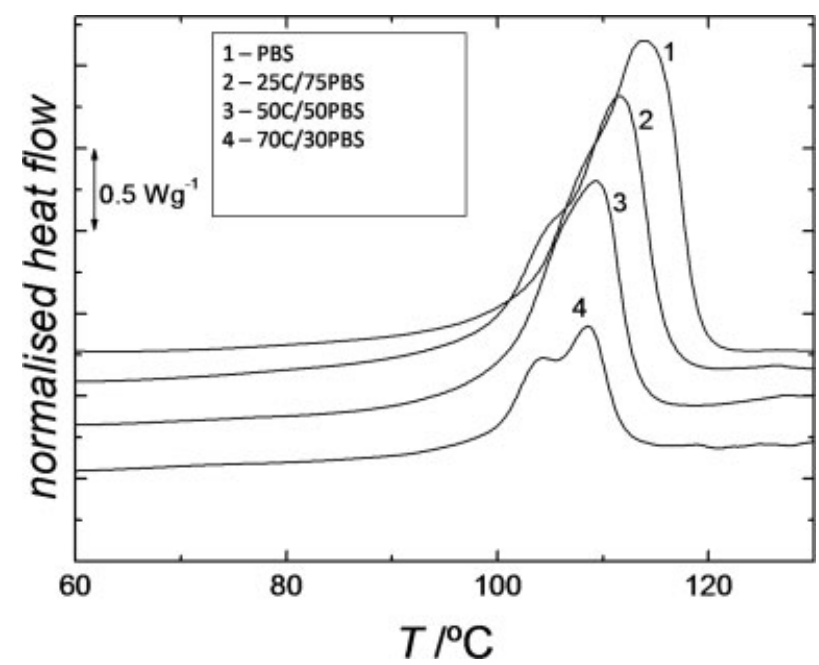

Figure 10. Normalized DSC thermograms (heat flow divided by the sample mass) of some PBS-based scaffolds of $60 \%$ porosity obtained at $20^{\circ} \mathrm{C} / \mathrm{min}$.

within brittle solids. ${ }^{29}$ The elastic buckling strength of foams is given as follows ${ }^{29}$ :

$$
\sigma_{\mathrm{b}}=\frac{n^{2} \pi^{2} E_{\mathrm{s}}}{12}\left(\frac{\rho_{\mathrm{FOAM}}}{\rho_{\mathrm{SOLID}}}\right)^{2}
$$

where $E_{\mathrm{s}}$ is the elastic modulus of the solid cell struts (assumed in our case to be equal to the modulus of the solid material) and $n^{2}$ is the end constraint factor that depends on stress state and buckling mode. The value of $n^{2}$ for biaxial compression is taken to be 0.36 . The buckling stress computed from Eq. (1) (data not shown) when compared to experimentally measured yield yielded a correlation coefficient $r^{2}=0.925$. Possible reasons for deviations include inhomogeneous density distribution leading to density gradient, ${ }^{28}$ kinks and wriggles in cell walls $^{34}$ or nonuniform material distribution in cell walls. ${ }^{35}$

\section{Differential scanning calorimeter}

For DSC analyses, scaffolds from chitosan/PBS blends and processed using salt particles of higher size range and with $60 \%$ porosity were selected. Normalized DSC scans of PBS-based materials were shown in Figure 10. The melting peak of the PBS fraction is visible in the thermograms, and the corresponding melting temperature and melting enthalpy are shown in Table IV. The crystallinity degree of the PBS component was calculated by knowing the theoretical value of $\Delta H_{\mathrm{m}}$ for $100 \%$ crystalline PBS, that was taken as $110.3 \mathrm{~J} / \mathrm{g}$, calculated on the basis of the group contribution method proposed by Van Krevelen. ${ }^{36}$ The melting temperature is found to decrease with increasing chitosan content, as detected before in injection-molded samples with the same composition. ${ }^{22}$ The same trend was also observed in blends of poly(3-hydrpxybutyrate) and chitosan, ${ }^{37}$ and attributed to strong intermolecular interactions between the chitosan and the polyester chains, resulting in thinner lamellar thickness crystals. However, despite this reduction of crystalline perfection, it was found that the total degree of crystallinity in the PBS fraction increased with increasing chitosan content. This suggests that, in this case, chitosan could act as a nucleating agent for PBS. The results (Fig. 10) also suggest that the melting peak may reflect the presence of two processes as, with increasing chitosan content a lower temperature shoulder is progressively enhanced. This may be an indication that chitosan may induce, in fact, the development of crystalline structures with a different lamellar morphology than that appearing in pure PBS. As such structures melt at lower temperatures, they should be composed of thinner lamellae. Comparing the thermal behavior of the scaffolds and the injection-molded compact samples made of the same materials, ${ }^{22}$ we may conclude that the former present lower melting temperature, indicating that shear can induce the production of more perfect/thicker crystalline structures.

\section{Crystallinity}

Small angle X-ray scattering

SAXS may provide further insights on the microstructure at the lamellae scale. The inset of Figure 11 shows, as a representative result, the 2D SAXS pattern of the 25/75 chitosan/PBS sample. As found in all the analyzed scaffolds, the results are consistent with the conventional lamellar structure, where the well-defined Debye ring is indicative that no preferential crystalline orientation exists. The 2D patterns were integrated using the X-ray software, version 1.0, allowing obtaining the intensity as a function of the scattering vector, $s$. Figure 11 shows some Lorentz-corrected scattering profiles for some analyzed

TABLE IV

Melting Temperature and Heat of Fusion of the PBS-Based Scaffold Materials

\begin{tabular}{lccc}
\hline Material & $T_{\mathrm{m}}\left({ }^{\circ} \mathrm{C}\right)$ & $\Delta H(\mathrm{~J} / \mathrm{g})$ & $x \%$ \\
\hline PBS & 104.3 & 60.8 & 55.1 \\
25C/75PBS & 102.3 & 52.9 & 63.9 \\
50C/50PBS & 100.1 & 37.5 & 68.0 \\
75C/25PBS & 99.3 & 19.6 & 71.1 \\
\hline
\end{tabular}

The degree of crystallinity within the PBS fraction is also included. 


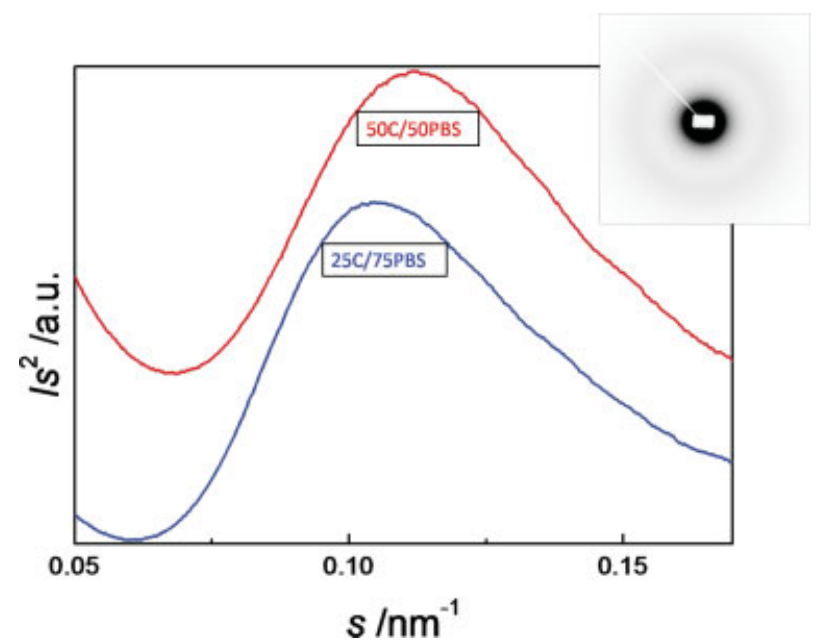

Figure 11. Lorentz-corrected SAXS profiles of some chitosan/PBS blends (60\% porosity), where the effect of chitosan content is investigated. Inset: 2D-SAXS pattern for the 25C/75PBS blend. [Color figure can be viewed in the online issue, which is available at www.interscience.wiley. com.]

PBS-based materials. The position of the peaks were used to calculate the average long period, $L=1 /$ $s_{\max }$. A slightly higher value of $L$ was found for the $50 / 50$ chitosan/PBS scaffold $(L=9.6 \mathrm{~nm})$ with respect to the other two materials $(L=8.9 \mathrm{~nm})$. An interesting result arises when one compares the morphology of such materials with those processed by injection molding, where the long period was found to be around $7.5 \mathrm{~nm} .^{22}$ This finding demonstrates the importance of the processing conditions on the developed morphology.

Wide angle X-ray scattering

Figure 12 shows the diffraction diagrams for some PBS-based scaffolds. The typical diffraction features of PBS are observed: peak at $2 \theta \approx 19.3^{\circ}$, assigned to the (111) and (002) planes, a peak of (110) at $2 \theta \approx$ $22.2^{\circ}$, with a shoulder at lower angles associated with the (012) planes, a peak of (121) at $2 \theta \approx 25.9^{\circ}$ and a peak of $(111)$ at $2 \theta \approx 29^{\circ}$. An electron diffraction study showed that PBS chains crystallize in monoclinic crystal lattice, with $a=0.523 \mathrm{~nm}, b=$ $0.908 \mathrm{~nm}, c=1.079 \mathrm{~nm}$, and $\beta=123.87^{\circ} .{ }^{38} \mathrm{No}$ change in peak position is found when the chitosan content changes. However, a close inspection on the half-width of the two major diffraction peaks, $\beta$, leads to the conclusion that the peaks are broader for the blend with 50\% chitosan than the blend with $25 \%$ chitosan. This would indicate that the size of the crystalline structures, $L_{h k l}$, is higher in the sample richer in PBS, as $L_{h k l}$ is intimately related to $\beta$ by the Scherrer's equation $^{39}: L_{h k l}=k \lambda /(\beta \cos \theta)$, where $k$ is an instrument constant and $\lambda$ is the wavelength of radiation used. This result correlates well with the DSC results, where from the analysis of the melting temperatures, it was possible to conclude that, with increasing chitosan content in the blends, the global crystalline structure of PBS would be more imperfect or characterized by thinner lamellae.

\section{Cytotoxicity evaluation}

Cytotoxic tests are a very important tool to evaluate a biomaterial in terms of toxic effect over cell growth and viability. L929 cells were exposed to extracts from the scaffolds for $72 \mathrm{~h}$ and the cellular response evaluated by MTS viability assay. In general, the MTS test results showed that L929 cells produced large amounts of a brown formazan product after incubation with the tested extracts. These results demonstrated that cells were viable, once they were able to incorporate and metabolize the substrate.

All materials, except the scaffolds composed by 50C/50PCL-60, 50C/50PCL-80 with pore size ranging between 63 and $125 \mu \mathrm{m}$ (Fig. 14), presented a high percentage of cell viability.

The extracts of scaffolds with larger pores (Fig. 13) showed cellular viability higher than $50 \%$ relative to the negative control. Extracts of scaffolds composed with HA (Fig. 13), irrespective of the percentage of HA, evidenced no adverse effects on cell viability and shown high values of cellular viability of $80 \%$ with respect to negative control.

A significant variability in the results of cytotoxicity of extracts from scaffolds of the same blend mix-

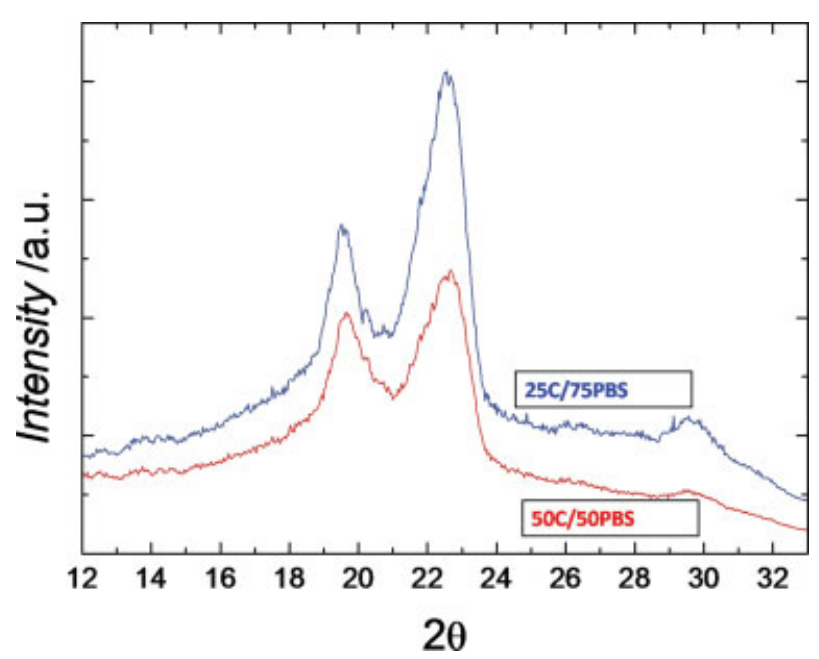

Figure 12. WAXS patterns for two different blends of chitosan and PBS (25/75 and 50/50) of scaffolds with $60 \%$ porosity. [Color figure can be viewed in the online issue, which is available at www.interscience.wiley.com.] 


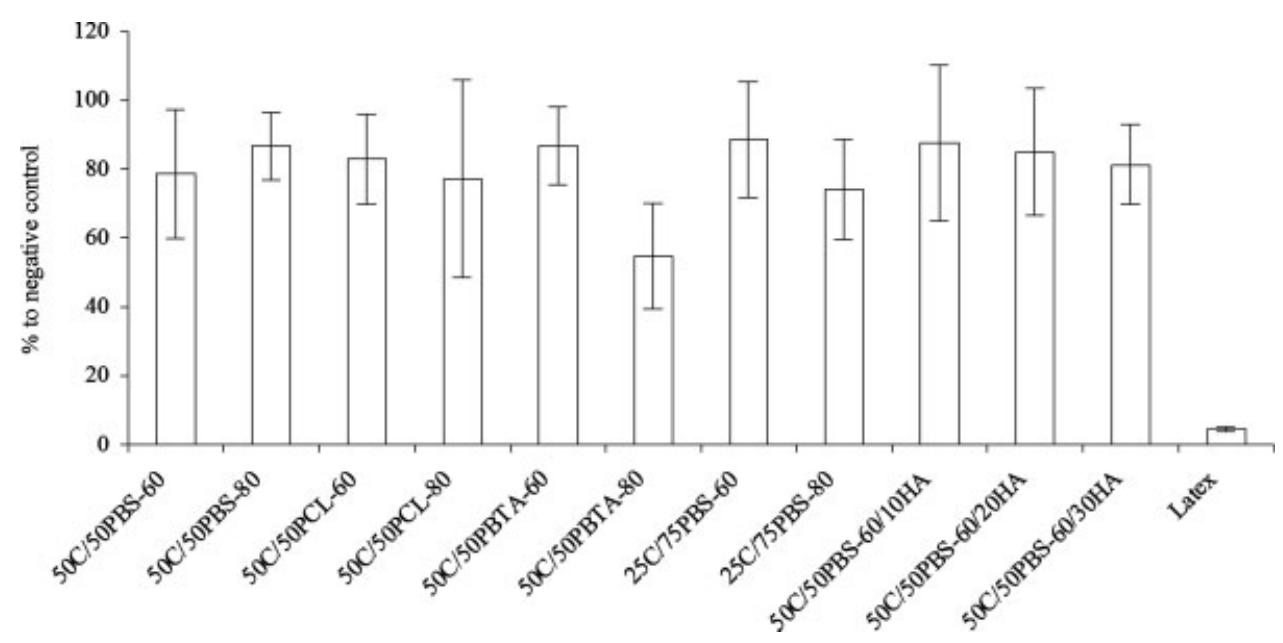

Figure 13. Cytotoxicity results of the 72-h extracts of scaffolds obtained with particle size range between 250 and $500 \mu \mathrm{m}$, namely 50C/50PBS-60, 50C/50PBS-80, 50C/50PCL-60, 50C/50PCL-80, 50C/50PBTA-60, 50C/50PBTA-80, 25C/75PBS-60, 25C/75PBS-80, 50C/50PBS/10HA-60, 50C/50PBS/20HA-60, 50C/50PBS/30HA-60, and positive control of cell death, latex. Results are based on optical density measurements, at OD of $490 \mathrm{~nm}$, and normalized for the negative control $(n=6$; \pm $\mathrm{SD} ; p<0.05)$.

ture was observed, with pore sizes ranging between 63 and $125 \mu \mathrm{m}$ (Fig. 14), evidenced by large standard deviation bars. This observation may be related with the morphology of the scaffolds, namely the pore size. Those scaffolds were produced by salt leaching using finer salt particles. The porogen size being smaller it may be more difficult to leach out all the salt particles, and it might be possible to have more particles entrapped in the scaffold structure. This may significantly influence the toxicity by the leach-

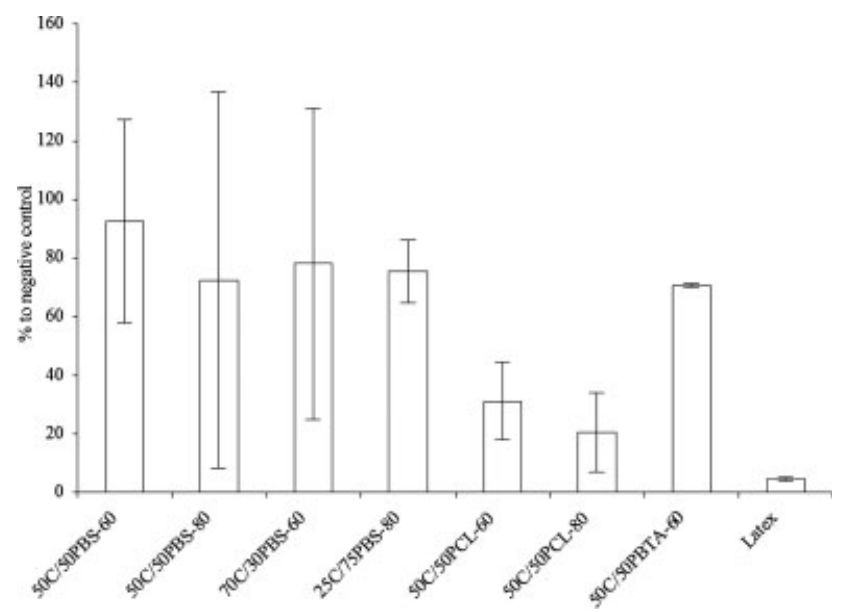

Figure 14. Cytotoxicity results of the 72-h extracts of scaffolds obtained with particle size ranging between 63 and $125 \mu \mathrm{m}$, namely 50C/50PBS-60, 50C/50PBS-80, 70C/ 30PBS-60, 25C/75PBS-80, 50C/50PCL-60, 50C/50PCL-80, 50C/50PBTA-60, and positive control of cell death, latex. Results are based on optical density measurements, at OD of $490 \mathrm{~nm}$, and normalized for the negative control $(n=6$; $\pm \mathrm{SD} ; p<0.05)$. able components released to the extract that will be in direct contact with cells.

Blends with PBS show the highest results of cell viability. In fact, an increase on the percentage of polyester is observed not to have direct influence in cell viability. A recent study of our group ${ }^{40}$ reports the osteogenic behavior of mesenchymal stem cells (MSCs) seeded and cultured onto $60 \%$ porosity scaffolds produced with 50C/50PBS, 50C/50PCL, and $50 \mathrm{C} / 50 \mathrm{PBT}$. The porogen size was in the range of 250-500 $\mu \mathrm{m}$. Results evidenced a remarkable cell behavior upon those chitosan-based scaffolds, in terms of cell adhesion and viability, as well the formation of mineralized extracellular matrix. The same compounds, but with $80 \%$ porosity and porogen particles with size of $65-125 \mu \mathrm{m}$, were studied for chondrogenic applications, with MSC differentiation toward a chondrogenic lineage, ${ }^{41}$ also showing excellent cell viability and activity when seeded at the surface of those materials.

The present study has shown only in one case, PCL/chitosan with smaller pore size, high values of toxicity of extracts from the scaffolds. However, it must be noted that this result was not confirmed for the same material in scaffolds with larger pore size. Thus, this exception in terms of cytotoxicity of extracts must be specifically caused by either the morphology of the scaffold or the preparation method and probably not by the materials.

Thus, the results herein reported of cytotoxicity of extracts from the scaffolds produced from novel developed chitosan-based blends show overall good viability of the cells (greater than $50 \%$ of the values of negative control) and those scaffolds will be further developed for various tissue engineering applications. 


\section{CONCLUSIONS}

In the present study, chitosan-based porous scaffolds with different architectures were produced by melt-based compression molding followed by salt leaching. The microarchitecture of the developed scaffolds was accessed by SEM and $\mu \mathrm{CT}$. By changing both the amount and average particle size of the porogen agent used, it was possible to prepare scaffolds with different macroscopic architecture using a melt-based approach. As expected, the amount of porosity was inversely proportional to the final mechanical properties of the developed scaffolds. For the scaffolds produced using similar particle size range, increasing the porosity decreased the yield stress and the compression modulus. Scaffolds prepared using particles of smaller size were observed to have lower compressive modulus than the ones prepared using a larger particle size range. Although contrary to the expected result, it was shown by analyzing the morphology to be consistent with the pore interconnectivity observed. Addition of chitosan increased the compressive modulus of the scaffolds produced using PCL and PBTA, but reduced the compressive modulus of those developed using PBS and PBSA. Addition of HA led to a decrease in the compressive yield stress and compressive modulus, probably because of the low interface adhesion. Thermal properties of chitosan-PBS-based scaffolds were analyzed, and it was found that the melting temperature decreased with increasing chitosan content. Microstructure analysis (WAXS and SAXS) demonstrated that with increasing chitosan content in the chitosan-PBS blends, the global crystalline structure of PBS would be more imperfect or characterized by thinner lamellae. Cytototoxic evaluation by means of MTS test revealed that L929 cells had similar metabolic activities to that obtained by the negative control. Therefore, the leachables released from the tested scaffolds could be considered as nontoxic and clearly cytocompatible.

The authors thank Patricia Malafaya and Adriano Pedro for the important help with the $\mu \mathrm{CT}$ data treatment. This work was carried out under the scope of the EU Integrated Project Genostem.

\section{References}

1. Langer R, Vacanti JP. Tissue engineering. Science 1993;260: 920-926.

2. Hutmacher DW. Scaffold design and fabrication technologies for engineering tissues-State of the art and future perspectives. J Biomater Sci Polym Ed 2001;12:107-124.

3. Muzzarelli RAA. Chitin. New York: Pergamon; 1977.

4. Klokkevold PR, Vandemark L, Kenney EB, Bernard GW. Osteogenesis enhanced by chitosan (poly- $N$-acetyl glucosaminoglycan) in vitro. J Periodontal 1996;67:1170-1175.
5. Peluso G, Petillo O, Ranieri M, Santin M, Ambrosio L, Calabro D, Avallone B, Balsamo G. Chitosan-mediated stimulation of macrophage function. Biomaterials 1994;15:1215-1220.

6. Baran ET, Reis RL. Use of chemically modified chitosan and other natural-origin polymers in tissue engineering and drug delivery. In: Reis RL, Roman JS, editors. Biodegradable Systems in Tissue Engineering and Regenerative Medicine. Boca Raton: CRC Press; 2005. p 325-335.

7. Sarasam A, Madihally SV. Characterization of chitosan-polycaprolactone blends for tissue engineering applications. Biomaterials 2005;26:5500-5508.

8. Zhang J, Wu L, Jing D, Ding J. A comparative study of porous scaffolds with cubic and spherical macropores. Polymer 2005;46:4979-4985.

9. McGlohorn JB, Holder WD Jr, Grimes LW, Thomas CB, Burg KJL. Evaluation of smooth muscle cell response using two types of porous polylactide scaffolds with differing pore topography. Tissue Eng 2004;10:505-514.

10. Lee WK, Ichi T, Ooya $T$, Yamamoto $T$, Katoh M, Yui N. Novel poly(ethylene glycol) scaffolds crosslinked by hydrolyzable polyrotaxane for cartilage tissue engineering. J Biomed Mater Res A 2003;67:1087-1092.

11. Kim SS, Sun Park M, Jeon O, Yong Choi C, Kim BS. Poly(lactide-co-glycolide)/hydroxyapatite composite scaffolds for bone tissue engineering. Biomaterials 2006;7:1399-1409.

12. Riddle KW, Mooney DJ. Role of poly(lactide-co-glycolide) particle size on gas-foamed scaffolds. J Biomater Sci Polym Ed 2004;15:1561-1570.

13. Hou Q, Grijpma DW, Feijen J. Preparation of interconnected highly porous polymeric structures by a replication and freeze-drying process. J Biomed Mater Res B 2003;67:732-740.

14. Wu L, Jing D, Ding J. A room-temperature injection moulding/particulate leaching approach for fabrication of biodegradable three-dimensional porous scaffolds. Biomaterials 2006;27:185-191.

15. Jeong SI, Kim SH, Kim YH, Jung Y, Kwon JH, Kim BS, Lee YM. Manufacture of elastic biodegradable PLCL scaffolds for mechano-active vascular tissue engineering. J Biomater Sci Polym Ed 2004;15:645-660.

16. Wu L, Zhang H, Zhang J, Ding J. Fabrication of three-dimensional porous scaffolds of complicated shape for tissue engineering. I. Compression molding based on flexible-rigid combined mold. Tissue Eng 2005;11:1105-1114.

17. Malda J, Woodfield TBF, Van Der Vloodt F, Wilson C, Martens DE, Tramper J, Van Blitterswijk CA, Riesle J. The effect of PEGT/PBT scaffold architecture on the composition of tissue engineered cartilage. Biomaterials 2005;26:63-72.

18. Lee SH, Kim BS, Kim SH, Kang SW, Kim YH. Thermally produced biodegradable scaffolds for cartilage tissue engineering. Macromol Biosci 2004;4:802-810.

19. Jung Y, Kim SS, Young HK, Kim SH, Kim BS, Kim S, Cha YC, Soo HK. A poly(lactic acid)/calcium metaphosphate composite for bone tissue engineering. Biomaterials 2005;26: 6314-6322.

20. Sun J, Wu J, Li H, Chang J. Macroporous poly(3-hydroxybutyrate-co-3-hydroxyvalerate) matrices for cartilage tissue engineering. Eur Polym J 2005;41:2443-2449.

21. Gomes ME, Godinho JS, Tchalamov D, Cunha AM, Reis RL. Alternative tissue engineering scaffolds based on starch: Processing methodologies, morphology, degradation and mechanical properties. Mater Sci Eng C 2002;20:19-26.

22. Correlo VM, Boesel LF, Bhattacharya M, Mano JF, Neves NM, Reis RL. Properties of melt processed chitosan and aliphatic polyester blends. Mater Sci Eng A 2005;403:57-68.

23. Correlo VM, Boesel LF, Bhattacharya M, Mano JF, Neves NM, Reis RL. Hydroxyapatite reinforced chitosan and polyester blends for biomedical applications. Macromol Mater Eng 2005;290:1157-1165. 
24. Ho ST, Hutmacher DW. Comparison of micro CT with other techniques used in the characterization of scaffolds. Biomaterials 2006;27:1362-2376.

25. Koza E, Leonowicz M, Wojciechowski S, Simancik F. Compressive strength of aluminium foams. Mater Lett 2003;58: 132-135.

26. Gibson LJ. Mechanical behavior of metallic foams. Annu Rev Mater Sci 2000;30:191-227.

27. Banhart J, Baumeister J. Deformation characteristics of metal foams. J Mater Sci 1998;33:1431-1440.

28. Beals JT, Thompson MS. Density gradient effects on aluminium foam compression behavior. J Mater Sci 1997;32:3595-3600.

29. Gibson LJ, Ashby MF. Cellular Solids Structure and Properties, 2nd ed. Cambridge, UK: Cambridge University Press; 1997.

30. Burdick JA, Frankel D, Dernell WS, Anseth KS. An initial investigation of photocurable three-dimensional lactic acid based scaffolds in a critical-sized cranial defect. Biomaterials 2003;24:1613-1620.

31. Ma PX, Choi JW. Biodegradable polymer scaffolds with welldefined interconnected spherical pore network. Tissue Eng 2001;7:23-33.

32. Landers R, Pfister A, Hubner U, John H, Schmelzeisen R, Mulhaupt R. Fabrication of soft tissue engineering scaffolds by means of rapid prototyping techniques. J Mater Sci 2002; 37:3107-3116.

33. Huang JS, Chou CY. Survival probability for brittle isotropic foams under multiaxial loading. J Mater Sci 2000;35:38813887.
34. Grenestedt JL. Influence of wavy imperfections in cell walls on elastic stiffness of cellular solids. J Mech Phys Solids 1998;46:29-50.

35. Simone AE, Gibson LJ. Aluminum foams produced by liquid-state processes. Acta Mater 46, 1998, 3109-3123.

36. Van Krevelen DW. Properties of Polymers. Amsterdam: Elsevier; 1990.

37. Cheung MK, Wan KPY, Yu PH. Miscibility and morphology of chiral semicrystalline poly-(R)-(3-hydroxybutyrate)/chitosan and poly-(R)-(3-hydroxybutyrate-co-3-hydroxyvalerate)/ chitosan blends studied with DSC, ${ }^{1} \mathrm{H} T_{1}$ and $T_{1} \mathrm{r}$ CRAMPS. J Appl Polym Sci 2002;86:1253-1258.

38. Ihn KJ, Yoo ES, Inn SS. Structure and morphology of poly (tetramethylene succinate) crystals. Macromolecules 1995;28: 2460-2464.

39. Alexander LE. X-ray Diffraction Methods in Polymer Science. New York: Wiley Interscience; 1969. p 137.

40. Costa-Pinto AR, Salgado AJ, Correlo V, Sol P, Bhattacharya M, Charbord P, Reis RL, Neves NM. Adhesion, proliferation and osteogenic differentiation of a mouse mesenchymal stem cell line (bmc9) seeded on novel melt based chitosan/polyester 3D porous scaffolds. Tissue Eng Part A 2008;94:1049-1057.

41. Oliveira JT, Correlo VM, Sol PC, Costa-Pinto AR, Salgado AJ, Bhattacharya M, Charbord P, Neves NM, Reis RL. Assessment of the suitability of chitosan/polybutylene succinate scaffolds seeded with mouse mesenchymal progenitor cells for a cartilage tissue engineering approach. Tissue Eng Part A 2008;14:1651-1661. 